\title{
A Paper-Based Ultrasensitive Optical Sensor for the Selective Detection of $\mathrm{H}_{2} \mathrm{~S}$ Vapors
}

\author{
Alejandro P. Vargas ${ }^{1}$, Francisco Gámez ${ }^{2, *}$ (D) Javier Roales ${ }^{1}\left(\mathbb{D}\right.$, Tânia Lopes-Costa ${ }^{1}$ and José M. Pedrosa ${ }^{1, * \mathbb{C}}$ \\ 1 Departamento de Sistemas Físicos, Químicos y Naturales, Universidad Pablo de Olavide, Ctra. Utrera km. 1, \\ 41013 Seville, Spain; apervar@alu.upo.es (A.P.V.); jroabat@upo.es (J.R.); tlopcos@upo.es (T.L.-C.) \\ 2 Departamento de Química Física, Universidad de Granada, Avenida de la Fuente Nueva s/n, \\ 18071 Granada, Spain \\ * Correspondence: fgammar@ugr.es (F.G.); jmpedpoy@upo.es (J.M.P.); Tel.: +34-958-243331 (F.G.); \\ +34-954349537 (J.M.P.)
}

Citation: Vargas, A.P.; Gámez, F.; Roales, J.; Lopes-Costa, T.; Pedrosa, J.M. A Paper-Based Ultrasensitive Optical Sensor for the Selective Detection of $\mathrm{H}_{2} \mathrm{~S}$ Vapors. Chemosensors 2021, 9, 40. https:// doi.org/10.3390/chemosensors 9020040

Academic Editor: Danila Moscone

Received: 7 January 2021

Accepted: 17 February 2021

Published: 19 February 2021

Publisher's Note: MDPI stays neutral with regard to jurisdictional claims in published maps and institutional affiliations.

Copyright: (c) 2021 by the authors. Licensee MDPI, Basel, Switzerland. This article is an open access article distributed under the terms and conditions of the Creative Commons Attribution (CC BY) license (https:// creativecommons.org/licenses/by/ $4.0 /)$.

\begin{abstract}
A selective and inexpensive chemical paper-based sensor for the detection of gaseous $\mathrm{H}_{2} \mathrm{~S}$ is presented. The triggering of the sensing mechanism is based on an arene-derivative dye which undergoes specific reactions in the presence of $\mathrm{H}_{2} \mathrm{~S}$, allowing for colorimetric analysis. The dye is embedded into a porous cellulose matrix. We passively exposed the paper strips to $\mathrm{H}_{2} \mathrm{~S}$ generated in itu, while the absorbance was monitored via an optic fiber connected to a spectrophotometer. The kinetics of the emerging absorbance at $534 \mathrm{~nm}$ constitute the sensor response and maintain a very stable calibration signal in both concentration and time dimensions for quantitative applications. The time and concentration dependence of the calibration function allows the extraction of unusual analytical information that expands the potential comparability with other sensors in the literature, as the limit of detection admissible within a given exposure time. The use of this specific reaction ensures a very high selectivity against saturated vapors of primary interferents and typical volatile compounds, including alkanethiols. The specific performance of the proposed sensor was explicitly compared with other colorimetric alternatives, including standard lead acetate strips. Additionally, the use of a smartphone camera to follow the color change in the sensing reaction was also tested. With this straightforward method, also affordable for miniature photodiode devices, a limit of detection below the ppm scale was reached in both colorimetric approaches.
\end{abstract}

Keywords: optical gas sensor; chemical sensors; toxic gases; colorimetric probes

\section{Introduction}

$\mathrm{H}_{2} \mathrm{~S}$ is a toxic, water-soluble, and flammable gas produced as a byproduct of a wide variety of industrial processes (petroleum and gas natural industries, coal mines, or paper, fertilizer and detergent production) or by the anoxygenic metabolism of some types of bacteria [1]. It is lethal at relatively low concentration levels [2] because it is absorbed by the lungs quickly, causing blood poisoning, headache and nausea, among other symptoms [3]. For instance, it causes loss of consciousness or death by respiratory paralysis by inhalation of 500-1000 ppm for $30 \mathrm{~min}$ [4]. Hence, this gas is regulated as toxic and dangerous according to the Occupational Safety and Health Administration (OSHA), that establishes an immediately dangerous to life and health limit of $100 \mathrm{ppm}$, a construction $8 \mathrm{~h}$ limit of $10 \mathrm{ppm}$, and a peak of up to $50 \mathrm{ppm}$ for $10 \mathrm{~min}$ for the general industry (ceiling permissible exposure limit, PEL-C) [5]. Despite this gas having a particular and unpleasant rotten egg smell that can be quickly detected by the human nose [6] with a sensitivity of 5-10 ppb, it cannot serve as a long-term $\mathrm{H}_{2} \mathrm{~S}$ detector because of olfactory fatigue. Precisely, one of the reasons why this gas is very dangerous is because at very low concentrations humans stop perceiving the smell that it produces due to the saturation of our very own gas detector, the pituitary gland. Therefore, there is a constant requirement to develop portable and real-time quantitative methods for low levels of $\mathrm{H}_{2} \mathrm{~S}$ in gas streams or the atmosphere. 
Additionally, the biological importance of this molecule is the justification of why some of the contemporary research efforts towards the optical detection of $\mathrm{H}_{2} \mathrm{~S}$ have been focused on solution or living cells [7-10]. Its importance as a biomarker has also been reported [11]. Overall, traditional solution methods [12-28] cope with fluorescence [29-35] and colorimetric sensors based on chromophores [36-44], organometallic complexes [45-48], or nanostructures [49-57], among others [58-64].

From a commercial perspective, the proper adaptation of the above-mentioned solution methods to gas phase sensors would allow the progressive substitution of the traditional gas phase detector tubes based on papers impregnated in metal salts such as lead (II) acetate [65], $\mathrm{CuSO}_{4}[66]$ or $\mathrm{Bi}(\mathrm{OH})_{3}$ [23]. The exploration of these cheaper and more eco-friendly colorimetric paper methodologies has been conducted for some analytes in the past [67-71]. Additionally, the increase in the quality / price ratio of digital cameras built into smartphones may help in the simplification and widening of the operativity of colorimetric sensors [72-84].

Here, we combine both approaches by developing a sensor for gaseous $\mathrm{H}_{2} \mathrm{~S}$ based on a paper substrate embedded with an arene-dye (bis(7-nitrobenzo[c][1,2,5]oxadiazol-4yl)sulfane) that serves as spectrophotometric probe. These types of molecules have been exploited as $\mathrm{H}_{2} \mathrm{~S}$ sensors in solution/biological environments [85-87], but no attempt to exploit its performance in gas phase sensors has been reported. Together with the unusual signal processing that enables us to extract important and general analytical information, the solution-to-gas phase conversion of the chemical probe is the main novelty of the present work and is of direct industrial interest. Besides being employed as a colorimetric probe for the detection of gaseous $\mathrm{H}_{2} \mathrm{~S}$ using laboratory equipment, the dye was also tested with a smartphone-based colorimetric methodology. Although the dynamic range is higher when the traditional spectrophotometry approach is employed, the limits of detection and quantification are well below the ppm in both cases.

\section{Materials and Methods}

\subsection{Chemicals}

Chemicals 4-chloro-7-nitro-1,2,3-benzoxadiazole (NBD-Cl), sodium sulfide hydrated $\left(\mathrm{Na}_{2} \mathrm{~S} \cdot \mathrm{xH}_{2} \mathrm{O}\right)$, methylamine, 2-mercaptoethanol, 1-butanethiol, hydrochloric acid and other reagents used as interferents or solvents were purchased from Sigma-Aldrich (Madrid, Spain) and used without further purification. The concentrations of hydrated $\mathrm{Na}_{2} \mathrm{~S}$ solutions were evaluated by titration with standardized $\mathrm{HCl}$.

\subsection{Synthesis}

\subsubsection{Preparation of 7-Nitrobenzo[c][1,2,5]Oxadiazole-4-Thiol (NBD-SH)}

Mixed methanolic solutions of $\mathrm{Na}_{2} \mathrm{~S} 1.02 \mathrm{mM}$ and NBD-Cl $0.51 \mathrm{mM}$ were prepared by dropwise addition of $\mathrm{Na}_{2} \mathrm{~S}$ while stirring. Once mixed, the solutions were kept under agitation for $1 \mathrm{~h}$ until a dark purple solution was formed.

\subsubsection{Preparation of (bis(7-Nitrobenzo[c][1,2,5]Oxadiazol-4-yl)Sulfane (NBD) ${ }_{2} \mathrm{~S}$}

Mixed methanolic solutions of NBD-Cl $1.50 \mathrm{mM}$ and $\mathrm{Na}_{2} \mathrm{~S} 0.75 \mathrm{mM}$ were prepared by dropwise addition of $\mathrm{Na}_{2} \mathrm{~S}$ while stirring. The solutions were kept under agitation for $3 \mathrm{~h}$ until a coppery-yellow solution with a precipitate was formed. This precipitate was then separated from the supernatant by means of 10 centrifuge cycles $(10 \mathrm{~min}$ at $5000 \mathrm{rpm}$ each, $66 \%$ yield). The resulting compound was characterized by electrospray ionization mass spectrometry (ESI-MS) and UV-Vis spectroscopy. ESI-MS spectra in positive mode displayed a main parent peak at $\sim 360 \mathrm{~m} / \mathrm{z}$ that matched with that of the thioether compound (see Figure S1). In diluted methanol solutions, the UV-Vis spectral features resembled those reported by Montoya et al. [85] This characterization constitutes direct proof of the purification of (NBD) ${ }_{2} \mathrm{~S}$ after the corresponding stoichiometric titration of NBD-Cl. It must be stressed that the procedure developed here constitutes a faster purification route than that described by Montoya et al. [85] Notably, the solution remained stable for at least 
1 year, as checked by UV-Vis spectroscopy (see Figure S2 of the Supplementary Materials for details).

\subsubsection{Sensor Preparation}

The sensor was prepared by adding $100 \mu \mathrm{L}$ of $(\mathrm{NBD})_{2} \mathrm{~S} 10 \mu \mathrm{M}$ in methanol to a $1 \mathrm{~cm} \times 2 \mathrm{~cm}$ strip of Whatman's chromatography paper (Whatman, Cat. No: 3001 604, Little Chalfont, UK) and dried in air. The transmittance of the paper was measured to be $\sim 80 \%$ at the excitation wavelength, high enough to ensure sensing in absorbance mode. The impregnating solution was diluted enough to avoid the precipitation of the thioether. This paper strip containing the sensing probe was then encapsulated between two glass plates attached to each other (hereafter referred to as the sensor). In this way, the chromatography paper was covered by the glass on both sides, producing a channel into which the gas could easily and homogeneously penetrate. Preliminary tests showed that this design maximized the interaction of the sensing part with the analyte. A scheme and some exemplifying photographs of the basic sensor setup are shown in Figure S3 for the sake of visualization.

\subsection{Sensing Experiments and Instrumentation}

\subsubsection{Mass Spectrometry}

Mass spectra were measured using a triple quadrupole system coupled to an Electrospray Source, Thermo Fisher TSQ Quantum Max (Thermo Fisher Scientific, Waltham, MA, USA). Spray voltage and capillary temperature were set at $3000 \mathrm{~V}$ and $35^{\circ} \mathrm{C}$, respectively. Full scan positive mode was selected to measure all positive ions generated in a $\mathrm{m} / \mathrm{z}$ range between 100 and 600. Scan time was set to $1 \mathrm{~s}$ and the acquisition time was $2 \mathrm{~min}$.

\subsubsection{Spectroscopy}

The spectroscopic measurements were carried out by means of a spectrophotometer (Ocean Optics USB4000, Ocean Optics, Orlando, FL, USA), a deuterium/tungsten lamp (DH-2000-BAL for paper sensor experiments and DT-MINI-2-GS for experiments in solution, Ocean Optics), and two $600 \mathrm{~nm}$ diameter optical fibers (Ocean Optics) coupled to collimating lenses before and after passing through the sample. The time step was set to $100 \mathrm{~ms}$.

\subsubsection{Exposure of $(\mathrm{NBD})_{2} \mathrm{~S}$ in Solution to Gaseous $\mathrm{H}_{2} \mathrm{~S}$}

Test experiments in methanol solutions were performed by bubbling the $\mathrm{H}_{2} \mathrm{~S}$ of the headspace of a reservoir dragged with a $\mathrm{N}_{2}$ flow of $0.1 \mathrm{~L} / \mathrm{min}$. The flow was controlled by a Bronkhorst F-201FV mass flow controller.

\subsubsection{Exposure of the Paper Sensor to Gaseous $\mathrm{H}_{2} \mathrm{~S}$}

Exposure to the gas was performed in a passive sampling manner at room temperature for $2 \mathrm{~min}$. Specifically, the sensor was fixed to one of the walls of a $4.5 \mathrm{~mL}$ quartz cuvette, keeping it out of contact with the analyte that was placed in the lower part. Gaseous $\mathrm{H}_{2} \mathrm{~S}$ was prepared in situ by the addition of $\mathrm{HCl}$ to $\mathrm{Na}_{2} \mathrm{~S}$ aqueous solutions. $\mathrm{HCl}$ concentration was always 20-fold higher than that of $\mathrm{Na}_{2} \mathrm{~S}$, to ensure the excess $\mathrm{HCl}$ for the reaction to be completed. The amount of $\mathrm{Na}_{2} \mathrm{~S}$ solution was selected according to the volume of the head space to provide the desired $\mathrm{H}_{2} \mathrm{~S}$ concentration in the sampling volume. The generated gas would subsequently interact with the sensor. Additionally, similar experiments were carried out by generating $\mathrm{H}_{2} \mathrm{~S}$ via the reaction $\mathrm{FeS}+2 \mathrm{HCl} \rightarrow \mathrm{FeCl}_{2}+\mathrm{H}_{2} \mathrm{~S}$.

\subsubsection{Camera-Based Color Recognition}

Pictures of the sensors were taken in raw image format with a resolution of 20 megapixels using the camera of a regular smartphone (Xiaomi M1805E10A). Constant and uniform artificial light was used for all pictures, with a white chromatography paper strip placed besides the sensor as a reference for the comparative analysis of the pictures and to con- 
trol for possible light fluctuations. Pictures were then processed using Adobe Photoshop CS6 (Adobe Inc., San Jose, CA, USA) without applying any color or exposure corrections. The color information for each of the sensor exposures was extracted using the major color spaces, namely CIELAB, RGB, HSB and CMYK. The analysis of the pictures revealed that the best characterization of our sensors corresponded to the $a^{*}$ parameter in the CIELAB color space, which accounts for the green-to-red palette.

\section{Results and Discussion}

The sensing mechanism for the detection of $\mathrm{H}_{2} \mathrm{~S}$ using $(\mathrm{NBD})_{2} \mathrm{~S}$ as a colorimetric probe is based on the formation of its synthesis precursor NBD-SH, which displays an intense absorption band centered at $534 \mathrm{~nm}$, as depicted in Figure 1. Figure 1a shows the chemical reaction pathway for the formation of $(\mathrm{NBD})_{2} \mathrm{~S}$ from $\mathrm{NBD}-\mathrm{Cl}$, and the corresponding solution UV-Vis spectra of the isolated species. According to Montoya et al. [85], NBD-Cl and other derivatives suffer a standard nucleophilic bimolecular $\mathrm{S}_{\mathrm{N} 2} \mathrm{Ar}$ addition from thiolcontaining species via formation of a Meisenheimer complex. The resulting thiol, NBD-SH, proceeds to the formation of the thioether (NBD) ${ }_{2} \mathrm{~S}$ under excess of NBD-Cl. The (NBD) ${ }_{2} \mathrm{~S}$ probe is insensitive towards thiol attack because of its electrophilicity. However, $\mathrm{H}_{2} \mathrm{~S}$ remains nucleophilic enough to attack the ipso carbon of the thioether and regenerate the thiol. The UV-Vis spectra of the compounds involved in the reaction (see Figure 1a) are shown in Figure 1b. NBD-Cl shows its maximum absorbance peak at $337 \mathrm{~nm}$. The spectral shapes of these bands are close to those reported by Montoya et al. [85], while the maxima of the absorption peaks at $543 \mathrm{~nm}$ for (NBD)SH and $406 \mathrm{~nm}$ for (NBD) ${ }_{2} \mathrm{~S}$ are slightly different from these prior results due to hydrogen bonding and polarity differences provoked by solvent effects.

(a)

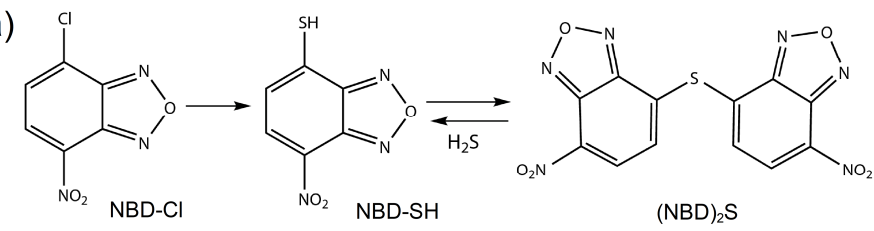

(b)

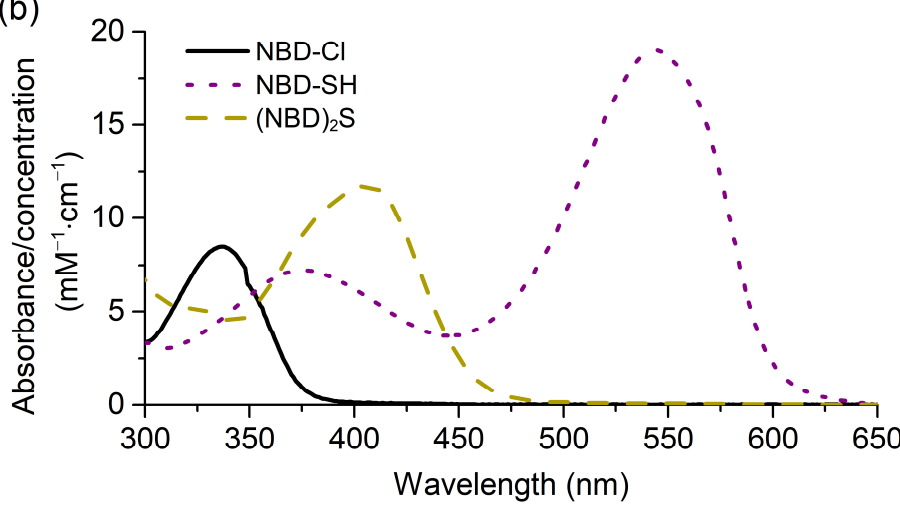

Figure 1. (a) Chemical reaction pathway of NBD derivatives involved in the sensing mechanism, namely NBD-Cl, NBD-SH and (NBD) ${ }_{2} \mathrm{~S}$. (b) UV-Vis spectra of NBD-Cl, NBD-SH and (NBD) ${ }_{2} S$ in diluted methanol solution.

The formation of NBD-SH in solution from isolated (NBD) ${ }_{2} \mathrm{~S}(32.5 \mu \mathrm{M})$ in the presence of bubbled $\mathrm{H}_{2} \mathrm{~S}$ at $750 \mathrm{ppm}$ is shown in Figure 2a over a time period of $90 \mathrm{~s}$. The absorbance of NBD-SH at $543 \mathrm{~nm}$ grows upon exposure to $\mathrm{H}_{2} \mathrm{~S}$, with an isosbestic point at $448 \mathrm{~nm}$ and a shift of the peak at $406 \mathrm{~nm}$ towards blue, which is clearly indicative of the formation of the thiol from the thioether. This last peak possesses contributions from the two involved species, denoting a partial consumption of (NBD) ${ }_{2} \mathrm{~S}$ due to its relative excess. The sensing reaction is easily detected with the naked eye by the appearance of a purple solution provoked by the electron delocalization in the deprotonated $\mathrm{S}^{-}$group within the 
aromatic moiety. The operativity of this set of coupled reactions has already been tested in solution; therefore, a question arises about its transferability to solid detectors.
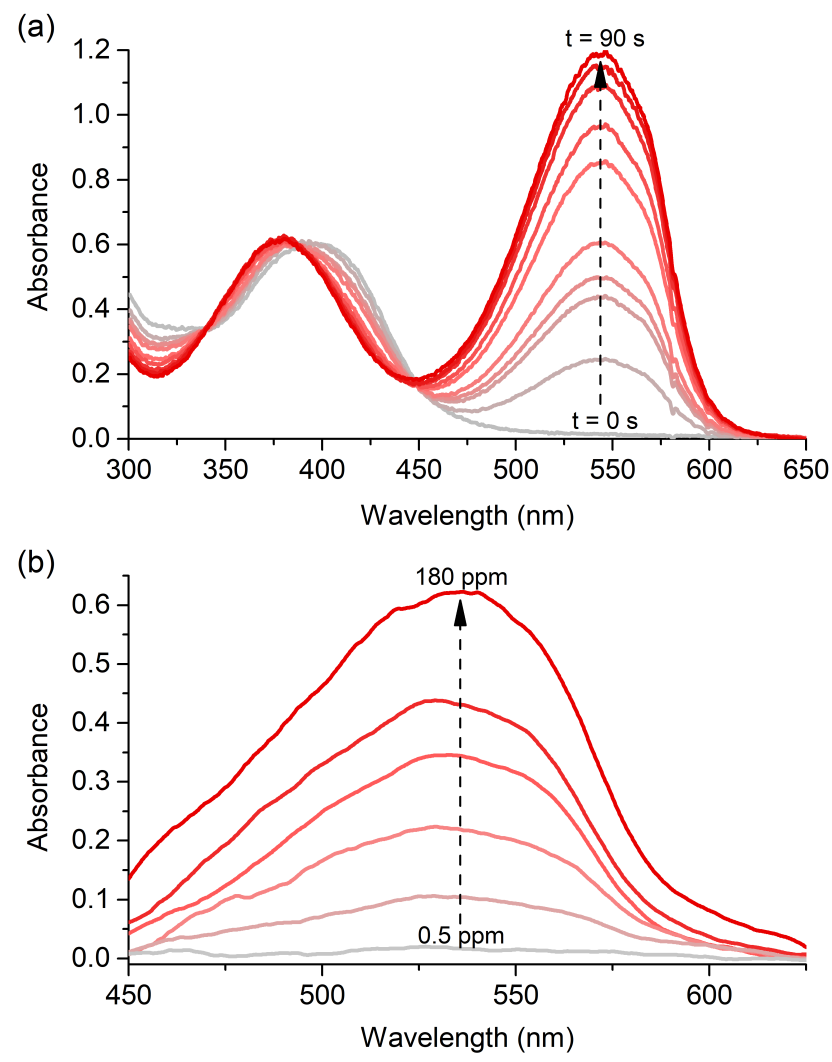

Figure 2. (a) Time-dependent response of the colorimetric probe. Exposure of a $32.5 \mu \mathrm{M}(\mathrm{NBD})_{2} \mathrm{~S}$ methanol solution to $750 \mathrm{ppm}$ of $\mathrm{H}_{2} \mathrm{~S}$ (bubbled in a $\mathrm{N}_{2}$ stream) in the $0-90 \mathrm{~s}$ range. (b) Spectral response of the embedded paper strip under an exposure of $15 \mathrm{~min}$ to $\mathrm{H}_{2} \mathrm{~S}$ atmospheres of different concentrations in the $0-180$ ppm range.

Hence, to alleviate the doubts concerning its applicability in solid-state gas sensors, paper strips embedded in (NBD) ${ }_{2} \mathrm{~S}$ were exposed to low and moderate concentrations of $\mathrm{H}_{2} \mathrm{~S}$ gas for $15 \mathrm{~min}$. As can be seen in Figure 2b, the formation of NBD-SH can be monitored by UV-Vis spectrophotometry, from a band centered at $\sim 534 \mathrm{~nm}$. The absorbance of this band increases with the concentration of the gas, allowing its use for quantification purposes. The shift and broadening of the thiol band can be ascribed to the infiltration into a porous substrate. We conclude that it is feasible to use a paper-based (NBD) ${ }_{2} \mathrm{~S}$ probe to detect $\mathrm{H}_{2} \mathrm{~S}$, even in the absence of any solvent. The direct reaction between (NBD) ${ }_{2} \mathrm{~S}$ and $\mathrm{H}_{2} \mathrm{~S}$ is ensured because of the porosity of the cellulose and the reaction time is maximized by the partial encapsulation of the strip (see methods above).

The highly specific reaction that takes place during the sensing process ensures the selectivity of the system. In Figure 3, this selectivity is demonstrated against a set of volatile compounds, including commonly used solvents, thiols, inorganic and organic acid and basic vapors, together with organic reductive compounds such as formaldehyde. We measured the absorbance of the sensor during its exposure to saturated vapors of these compounds and compared their corresponding signal with that produced by a reference atmosphere containing $50 \mathrm{ppm} \mathrm{H}_{2} \mathrm{~S}$. Although in all cases the gas concentration of the interferent was substantially higher than that of $\mathrm{H}_{2} \mathrm{~S}$, exposure to the latter always led to the greatest changes in absorbance. Of all the selected potential interferents, only 2-mercaptoethanol, formaldehyde and 1-butanethiol produced clearly measurable changes in the sensor. This change was, however, 125-, 4900- and 9600-fold smaller, respectively, than that induced by $\mathrm{H}_{2} \mathrm{~S}$, at the same concentration. Additionally, we confirmed 
that dry $\mathrm{N}_{2}$ did not produce any change in the sensor, and no influence of the air humidity was observed when we exposed the paper strips to humidity generated by water reservoirs or dry $\mathrm{N}_{2}$. We observed that the sensors deteriorated within a week after their fabrication. However, the long-term stability of $(\mathrm{NBD})_{2} \mathrm{~S}$ in solution (at least up to a year) and the easy procedure for the preparation of the embedded paper strips would allow for the straightforward fabrication of sensors immediately prior to their use in the required environment.

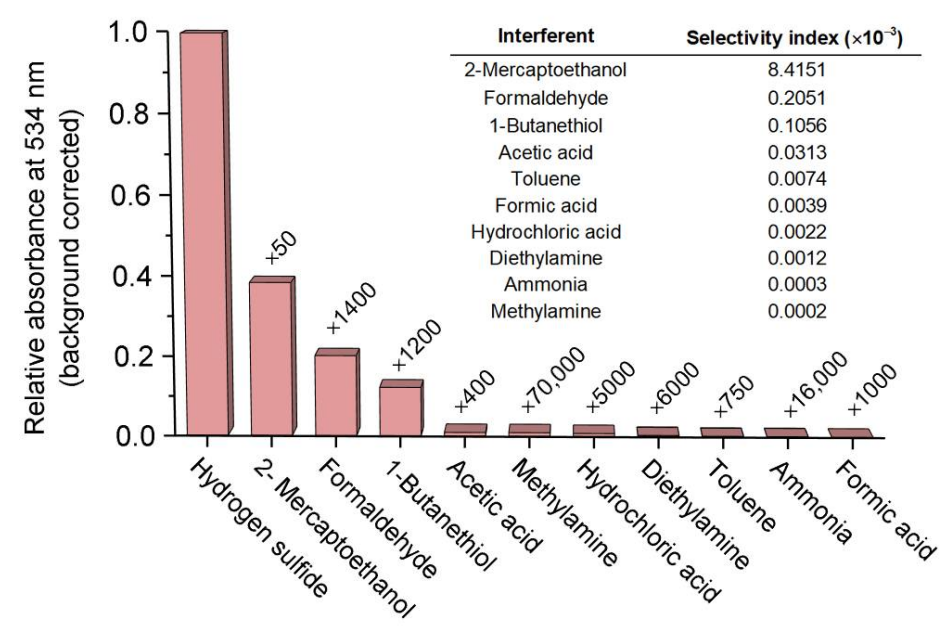

Figure 3. Effects of various saturated vapors on the absorbance at $534 \mathrm{~nm}$ of the paper strip containing $(\mathrm{NBD})_{2} \mathrm{~S} . \mathrm{H}_{2} \mathrm{~S}$ was considered as a reference with a concentration of $50 \mathrm{ppm}$. The relative concentrations of the interferents are denoted on top of each bar. The inset chart shows the selectivity index for each vapor as defined in the text.

To quantify the sensor selectivity, we evaluated the selectivity index $\mathrm{K}_{\mathrm{I} / \mathrm{A}}$, defined as the signal-to-concentration ratio for the interferent gas divided by that of the target analyte $\left(\mathrm{H}_{2} \mathrm{~S}\right)$ after a $15 \mathrm{~min}$ exposure. The values of $\mathrm{K}_{\mathrm{I} / \mathrm{A}}$ for each interferent are included as an inset chart in Figure 3. The very low values obtained in all cases further confirm the high selectivity of the sensor and indicate that, despite the high relative concentration of the interferents, the exposure to $\mathrm{H}_{2} \mathrm{~S}$ was responsible for a distinctive and intense modification of the spectral properties of the colorimetric probe.

We analyzed the temporal variations in the sensor responses to increasing concentrations of $\mathrm{H}_{2} \mathrm{~S}$ gas in the $0-250 \mathrm{ppm}$ concentration range by monitoring the backgroundcorrected absorption at the wavelength of maximum change $(534 \mathrm{~nm}) \Delta \mathrm{A}_{534}$. The temporal evolution of the signal $S=\Delta \mathrm{A}_{534}-\mathrm{A}_{700}$ is provided in Figure 4a for a set of $\mathrm{H}_{2} \mathrm{~S}$ concentrations in the above-mentioned range. It should be noted that the background signal at $700 \mathrm{~nm}$ was subtracted from that at $534 \mathrm{~nm}$ to account for changes in the baseline due to detector drifts. The sigmoidal-shaped sensing kinetics were fitted to non-linear ad hoc functions of the form:

$$
S(c, t)=\mathrm{A}_{\infty}(c)|\tanh [k(c) t / 2]|,
$$

where $A_{\infty}$ is the saturation value of the signal at a certain analyte concentration, $c$, which is ensured by the hyperbolic tangent function that contains the time $(t)$ dependence. $k$ is the parameter that defines the curvature of the $S$-shaped curve at short times. The fitting data are plotted as continuous red lines in Figure 4a. This functionality was selected after a hard trial-and-error procedure, and, as a result, the fitted parameters are simple functions of the $\mathrm{H}_{2} \mathrm{~S}$ concentration $c$. Specifically, for time units in min and $c$ in ppm, $\mathrm{A}_{\infty}(c)=0.06449 \cdot c^{0.43644}\left(\mathrm{R}^{2}=0.99420\right)$ and $k(c)=0.17738+0.00163 \cdot c\left(R^{2}=0.99985\right)$, which enables a wide dynamic range with a lower limit of about $0.05 \mathrm{ppm}$ and short sampling times (see below). These coefficients are shown in Figure S4 of the Supplementary Materials. The fit provides an average coefficient of determination of $\left\langle R^{2}\right\rangle=0.99982$ in 
the considered time and concentration ranges. Such agreement allows us to confidently extrapolate important analytical information, as explained in the next paragraph.
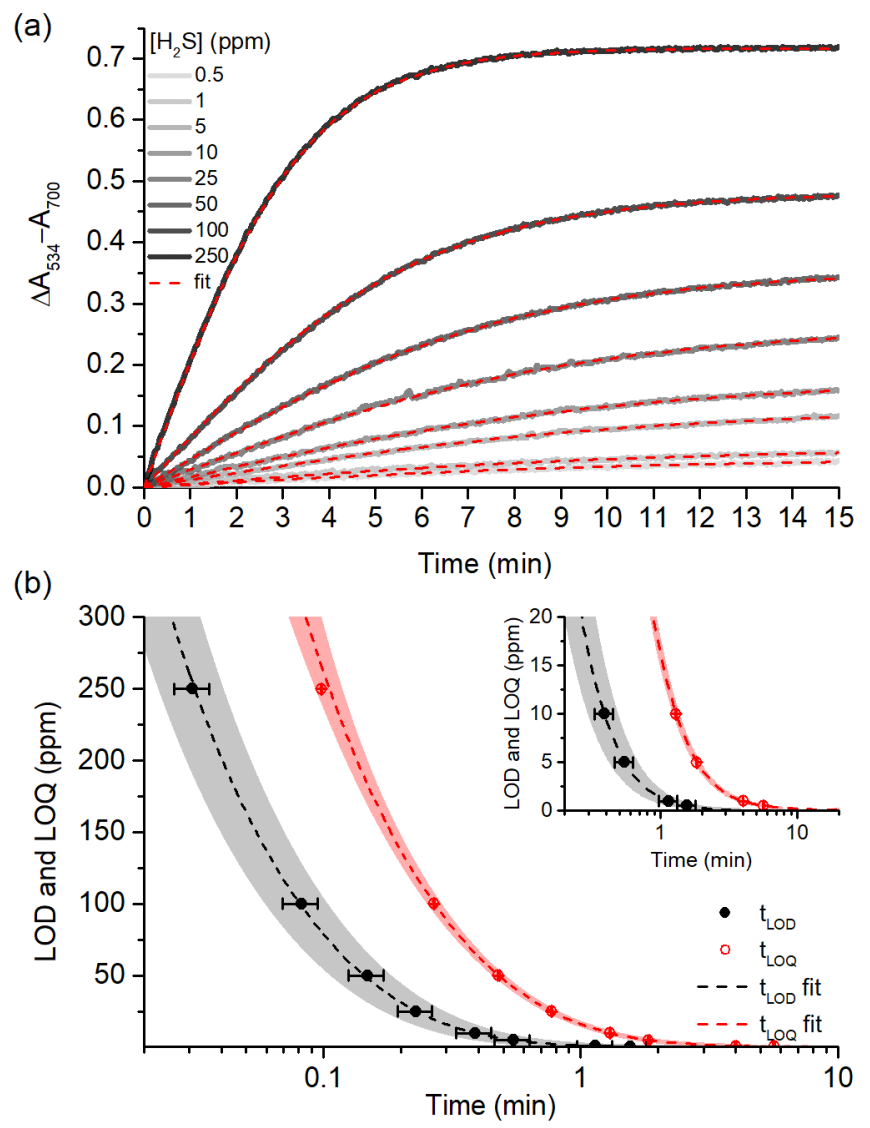

Figure 4. (a) Kinetics for the colorimetric signal $S(t)$ (see text for details) of the sensor as a function of the $\mathrm{H}_{2} \mathrm{~S}$ concentration in the passive sampling experiment. Grayscale lines indicate the experimental data, while red dashed lines correspond to the sigmoidal fits described in the text (see Equation (1)). (b) Semilog plots of the experimental LOD $(S / N=3)$ and LOQ $(S / N=10)$ values for different exposure times (symbols). Dashed lines correspond to the analytical inversion of Equation (1). Shaded regions correspond to the error limits obtained from the fitting function, and the error bars stand for the experimental error $( \pm 1 \sigma)$ of triplicate experiments. Inset shows the low concentration region.

The signal evolves with time; therefore, we have first calculated the steady-state or "asymptotic" limits of detection $\left(\mathrm{LOD}_{\infty}\right)$ and quantification $\left(\mathrm{LOQ}_{\infty}\right)$ as $\mathrm{A}_{\infty}=\alpha \mathrm{N}$ where $\alpha=3\left(\mathrm{~A}_{\infty}=\mathrm{LOD}_{\infty}\right)$ or $10\left(\mathrm{~A}_{\infty}=\mathrm{LOQ} \infty\right)$, and $N$ is the instrumental noise extracted from the arithmetic mean of ten blank experiments. Statistical errors are evaluated by error propagation. These parameters provide information about the minimum detectable and quantifiable concentrations at a time $t \rightarrow \infty$. The resulting values are $\mathrm{LOD}_{\infty}=5.4 \pm 1.5 \mathrm{ppb}$ and $\mathrm{LOQ}_{\infty}=86 \pm 23 \mathrm{ppb}$. From the root of the fitting function, the more useful parameters $\mathrm{LOD}_{t}$ and $\mathrm{LOQ}_{t}$ can also be evaluated. They are defined as the minimum detectable and quantifiable concentration within a period of $t \mathrm{~min}$. These obtained values are $\mathrm{LOD}_{15}=0.008 \pm 0.002 \mathrm{ppm}$ and $\mathrm{LOQ}_{15}=0.12 \pm 0.03 \mathrm{ppm}$ for an exposition time of $15 \mathrm{~min}$, and $\mathrm{LOD}_{10}=0.012 \pm 0.003 \mathrm{ppm}$ and $\mathrm{LOQ}_{10}=0.19 \pm 0.04 \mathrm{ppm}$ for $10 \mathrm{~min}$ exposures. This last value is well above the PEL-C. Finally, the time required to obtain a signal equal to $\alpha \mathrm{N}$ at each concentration is extracted from both the experiments and the analytical inversion of Equation (1). The results are plotted in Figure 4b. The shaded regions indicate the limits extracted from the error propagation of the analytical inversion of Equation (1). Both LOD and LOQ decrease quasi-exponentially with the exposition time.

A comparative study with both colorimetric commercial methods and results published in the scientific literature for the detection of gaseous $\mathrm{H}_{2} \mathrm{~S}$ postulates our sensor 
as a feasible alternative in the field. Most contributions reported sensors with relatively high LOD (see, for instance, refs [21,30]), with no calibration or selectivity data in some cases [88], here we focus on some examples of colorimetric approaches with the lowest LODs found in the literature. Sen et al. [38] reported a "limit of detection" of $50 \mathrm{ppb}$ upon $15 \mathrm{~min}$ exposure, which is more than six-fold higher than our measured value. For their part, Tanaka et al. [40] provided an $\mathrm{LOD}_{60}=19 \mathrm{ppb}$, also much higher than our predicted value according to the extrapolation in Figure $4 \mathrm{~b}$. Our results are also favorable against naked-eye sensors based on $\mathrm{Bi}(\mathrm{OH})_{3}$ [23] and some fluorescence methods [31]. The proposed chemical probe is free of heavy metal compounds, which plays right into our approach against other reported methods. This is the case of the interesting work by Silveira da Petrucci and Cardoso [35], in which a Hg-based fluorescent probe is employed in a paper-based method with $\mathrm{LOD}_{1}=3 \mathrm{ppb}$, estimated out of the linear calibration region.

On the other hand, comparison with commercial tubes is not an easy task because, in most cases, companies do not provide measuring times. Some stroke tubes based on heavy metals are reported to have $\mathrm{LOQ}_{2}=2 \mathrm{ppm}$ (lead acetate based, Sensidyne, LP) [65] or $\mathrm{LOQ}_{3}=0.1 \mathrm{ppm}$ (tubes based on $\mathrm{HgCl}_{2}$, Rae Systems, Inc. (San Jose, CA, USA) [89], close to our values of $\mathrm{LOQ}_{2}=0.16 \pm 0.03 \mathrm{ppm}$ and $\mathrm{LOQ}_{3}=0.12 \pm 0.03 \mathrm{ppm}$. The company Gastec has developed metal-free colorimetric tubes for the detection of $\mathrm{H}_{2} \mathrm{~S}$, ranging from 0.2 to $4000 \mathrm{ppm}$. The most effective (hydrogen sulfide $4 \mathrm{HT}$, Gastec Corporation, Fukayanaka, Japan) [66] has an $\mathrm{LOD}_{3}=0.05 \mathrm{ppm}$, also comparable to the evaluated $\mathrm{LOD}_{3}=0.05 \pm 0.01 \mathrm{ppm}$ for our paper strips. In relation with the classical use of lead (II) acetate, it must be mentioned that the original version of lead acetate paper tapes gave LODs of 5-10 ppm, considerably higher than the value provided here. Although it has been recognized that these classical tapes, besides being ecologically questionable, are strongly dependent on ambient humidity [90] (which is not the case with our sensor), some improvements on the use of this compound are still underway on the scientific community. For instance, one colorimetric approach led to an LOD of $400 \mathrm{ppb}$ [44]. Additionally, some complex instrumental refinements available in the market provide upgraded performance with respect to our colorimetric approach. As an example, the proposal reported by Innov Analysis Systems (Issoudun, France) [91] with an LOD $_{0.33}=5$ ppm compares favorably against our value of $13.6 \mathrm{ppm}$. However, it must be noted that several compounds, such as mercaptans, are strong interferents for the detection systems behind many of these commercial tubes. In contrast with our proposal, this may limit their usability in certain atmospheres and needs to be carefully considered when comparing and selecting appropriate detectors for each scenario.

In principle, the calibration of the absorbance kinetics provided by Equation (1) enables the quantification of the $\mathrm{H}_{2} \mathrm{~S}$ concentration by measuring the signal at any time or the kinetics over a (narrow) period. This calibration also encompassed the long-time behavior through $\mathrm{A}_{\infty}$. The precision and accuracy of the calibration was assessed with three blind experiments covering a wide concentration range. The results obtained with the fit of the kinetics over 15 min to Equation (1) were $4047 \pm 3,11,577 \pm 6$ and 153,339 \pm 34 ppb. In comparison with the concentrations obtained with the $\mathrm{A}_{\infty}$ values, the absolute errors are recurrently higher in this case, although the average least significant difference between both calibration methods is $0.6 \mathrm{ppm}$. It can be concluded that Equation (1) provides an adequate calibration function because it allows the extraction of the $\mathrm{H}_{2} \mathrm{~S}$ concentration faster than that obtained via $\mathrm{A}_{\infty}$, although both methods are equally usable on the condition that the $\mathrm{H}_{2} \mathrm{~S}$ concentrations were high enough to ensure a fast saturation value. Additionally, we have performed a set of three experiments in which the $\mathrm{H}_{2} \mathrm{~S}$ vapors were produced in situ by the reaction of $\mathrm{FeS}$ with $\mathrm{HCl}$. Given the difficulties to obtain $\mathrm{H}_{2} \mathrm{~S}$ samples produced naturally, meaning without human intent, we deemed it appropriate to include this second source of $\mathrm{H}_{2} \mathrm{~S}$ in our analysis. Besides being of educational interest, it is also of importance in the oil and natural gas industry because of the common formation of sulfide scales [92]. The target $\mathrm{H}_{2} \mathrm{~S}$ concentrations in our experiments span the 5-280 ppm range. The difference between the nominal and the calculated concentration 
after $2 \mathrm{~min}$ exposure led to an average absolute deviation of $\left\langle\Delta_{m}\right\rangle=0.6 \mathrm{ppm}$. Experimental results are shown in Figure S5. These tests validate our sensor against another (dry) $\mathrm{H}_{2} \mathrm{~S}$ source and demonstrate its analytical robustness. Finally, it should be mentioned that the consistency between both generation methods constitutes a double check of the humidityindependent kinetics provided by the specific reaction driving the sensing mechanism. To emphasize the negligible effect of humidity conditions, the effect of water vapors on the sensor absorbance is included in Figure S5.

Finally, camera-based color recognition was also assessed as a simple colorimetric alternative for the detection of $\mathrm{H}_{2} \mathrm{~S}$. Among the major color spaces, CIELAB offered the best results. CIELAB, or $L^{*} a^{*} b^{*}$, is a robust $3 \mathrm{D}$ color-space that maps the visible spectrum in terms of three coordinates, namely, $L^{*}$ which represents the luminosity (with values ranging $0-100$ ); $a^{*}$, which accounts for the green-to-red palette (negative for green and positive for red); and $b^{*}$, which collects information about the blue-to-yellow coordinate (negative for blue and positive for yellow). In Figure 5, we show the variation of the $a^{*}$ coordinate as a function of the $\mathrm{H}_{2} \mathrm{~S}$ concentration. This parameter was obtained from photographs of the embedded paper strips taken after an exposure of $15 \mathrm{~min}$ to $\mathrm{H}_{2} \mathrm{~S}$. It is quite apparent that saturation is reached above $\sim 1.5 \mathrm{ppm}$, but a linear region $\left(\mathrm{R}^{2}=0.99070\right)$ can be found between 0 and $1.5 \mathrm{ppm}$. Although the operation and dynamics ranges were smaller than those obtained with spectroscopy, the $\mathrm{LOD}_{15}$ and $\mathrm{LOQ}_{15}$ (obtained as $\alpha \sigma_{b} / m$, where $\sigma_{b}$ is the standard deviation of the intercept and $m$ is the slope of the calibration line) were $106 \pm 4 \mathrm{ppb}$ and $355 \pm 14 \mathrm{ppb}$, respectively, values that are still competitive with commercial tubes and only $\sim$ three-fold higher than those obtained with the traditional spectrophotometer-based colorimetric approach. Multiple linear regression was also tested, employing $n=7$ points of the three $L^{*} a^{*} b^{*}$ coordinates and $\mathrm{H}_{2} \mathrm{~S}$ concentration as the dependent variable. This led to an equation of the form $\left[\mathrm{H}_{2} \mathrm{~S}\right]=-1.6779+0.0076 \cdot L^{*}+$ $0.2547 \cdot a^{*}+0.0499 \cdot b^{*}$, with $R^{2}=0.98895$. The randomness of the residual patterns shown in Figure S5 indicates the suitability of the model. The LOD was evaluated to be $109 \pm 2 \mathrm{ppb}$ according to Bro et al. [93] from the calibration line between predicted and nominal $\mathrm{H}_{2} \mathrm{~S}$ concentrations $\left(R^{2}=0.99832\right.$, see Figure S7). This option was, however, set aside because of its relative smaller coefficient of determination and the inherent statistical difficulty in the evaluation of the LOD/LOQs and reliable associated errors within partial least-squares fits.

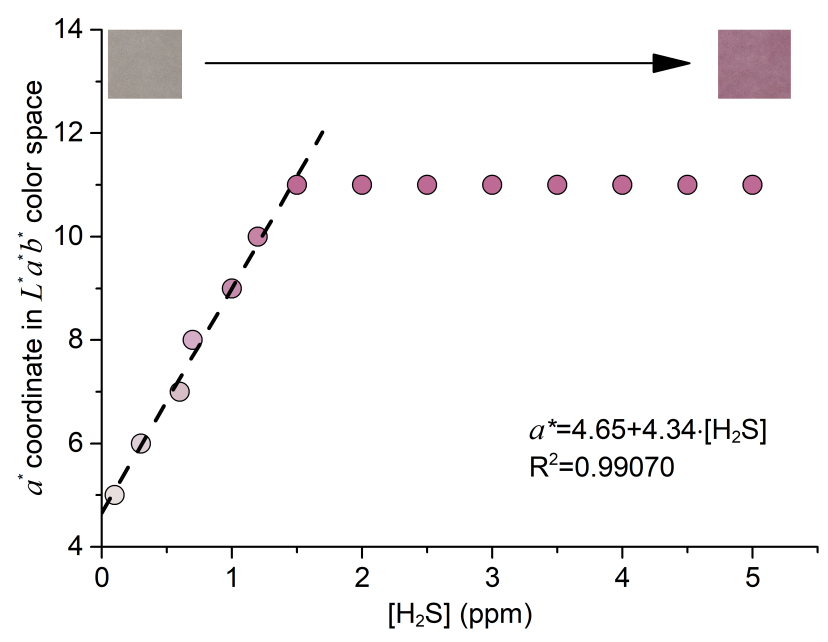

Figure 5. Colorimetric response of the paper strips mapped in the $a^{*}$ coordinate of the CIELAB colorspace. The color of the dots corresponds to the extracted color of the sensor at each concentration. Calibration line in the low-concentration region is added as a dashed line. The linear calibration curve and coefficient of determination are also typed in the graph. Photographs of the unexposed paper (left) and color-saturated sensor (right) are included for the sake of visualization. Values were obtained as the nearest integer of the average of three independent experiments. 
Both the $a^{*}$ parameter analysis and the multiple linear regression obtained from all three $L^{*} a^{*} b^{*}$ coordinates show that, within their limitations, any smartphone camera can be used to quantify the color change produced by our sensor. Photodetectors inside digital cameras work in a similar way as those implemented in any regular spectrophotometer and; despite their spectral resolution being lower, they can be used for color measurements. With digital cameras incorporated in every smartphone, these present clear advantages in terms of availability and affordability in comparison with regular spectrophotometers. An exhaustive comparison between both methods is beyond the scope of this work, but we consider camera-based color recognition to be a plausible alternative to spectrophotometers in those cases where the required spectral range allows for it. In our case, the combination of the proposed paper-based sensor with smartphone-assisted color measurement could result in a portable, straightforward, and inexpensive system for the detection of gaseous $\mathrm{H}_{2} \mathrm{~S}$.

\section{Conclusions}

We present a simple experimental procedure for the construction of a disposable and selective paper-based sensor for the spectroscopic quantification of $\mathrm{H}_{2} \mathrm{~S}$ vapors. The method exploits the specific bimolecular nucleophilic aromatic substitution of arene-derivative dyes that can be easily transferred to a solid support to obtain a gas detector. The colorimetric signal of the device upon its exposure to $\mathrm{H}_{2} \mathrm{~S}$ led to particular and selective spectral changes whose temporal evolution could be evaluated either with UV-Vis spectroscopy or image processing. Although the concentration and temporal ranges for the quantification in each optical method differ substantially, we were able to use the compiled data as input in calibration procedures, which allowed for the temporal detection and quantification of $\mathrm{H}_{2} \mathrm{~S}$ with low LOD/LOQs. The results obtained from UV-Vis spectroscopy enabled us to reach better LOD/LOQs than most commercial methods based on poisonous transition metal salts such as lead or mercury. In addition, we have demonstrated that it is possible to perform a direct calibration at low $\mathrm{H}_{2} \mathrm{~S}$ concentrations through the color extraction of digital pictures taken with a regular smartphone, broadening the potential range of use of our disposable sensor.

Supplementary Materials: The following are available online at https: / www.mdpi.com/2227-9 040/9/2/40/s1, Figure S1. ESI mass spectra of the synthesized (NBD)2S powder $(30 \mu \mathrm{g} / \mathrm{mL}$ in methanol); Figure S2. Stability of the synthesized (NBD)2S in methanol. The gray area indicates the absorb-ance range covered by $\pm 1 \sigma$ of the initial absorbance averaged over triplicate independent samples. The maximum relative absorbance with respect to the initial value is $\sim 6 \%$ within this temporal window; Figure S3. Details of the experimental setup for the passive sampling of the sensor to H2S. See main text for details; Figure S4. Concentration dependence of the fitting coefficients describing the kinetics of the back-ground-corrected absorbance. Symbols stand for data extracted from the experimental data and the lines correspond to the fit written in each graph. See main text for details; Figure S5. Experimental kinetics and analytical fitting of the kinetic experiments performed by generating $\mathrm{H} 2 \mathrm{~S}$ vapors by the reaction of $\mathrm{FeS}$ with $\mathrm{HCl}$ and the sensor exposure to water vapours; Figure S6. Residual plot for the multiple linear regression performed in the CIELAB color-space from the sensor photographs. See main text for details; Figure S7. Linear calibration constructed from the [H2S] predicted with the multiple linear regres-sion against the nominal [H2S].

Author Contributions: Conceptualization, T.L.-C. and J.M.P.; formal analysis, F.G.; funding acquisition, F.G. and J.M.P.; investigation, A.P.V.; methodology, A.P.V., F.G., T.L.-C. and J.M.P.; project administration, J.M.P.; software, J.R.; validation, A.P.V.; visualization, J.R.; writing-original draft preparation, F.G. and J.R.; writing-review and editing, J.R., T.L.-C. and J.M.P. All authors have read and agreed to the published version of the manuscript.

Funding: Funding from the Operative Programme FEDER-Andalucia (2014-2020, objective 1.2.2., A1122062E0) through project AT17-5549 from the Junta de Andalucía (CECEU) is gratefully acknowledged. Funding from the State Research Agency of Spain through projects PID2019-110430GB-C22, PID2019-105195RA-I00 and PCI2020-112241 also contributed to the present research.

Institutional Review Board Statement: Not applicable. 
Informed Consent Statement: Not applicable.

Acknowledgments: Thanks to the Mass Spectrometry and Laser Spectroscopy group of the Pablo de Olavide University for their assistance during the mass spectrometry experiments.

Conflicts of Interest: The authors declare no conflict of interest.

\section{References}

1. Dorman, D.C.; Brenneman, K.A.; Struve, M.F.; Miller, K.L.; James, R.A.; Marshall, M.W.; Foster, P.M.D. Fertility and developmental neurotoxicity effects of inhaled hydrogen sulfide in Sprague-Dawley rats. Neurotoxicol. Teratol. 2000, 22, 71-84. [CrossRef]

2. Struve, M.F.; Brisbois, J.N.; Arden James, R.; Marshall, M.W.; Dorman, D.C. Neurotoxicological effects associated with short-term exposure of Sprague-Dawley rats to hydrogen sulfide. Neurotoxicology 2001, 22, 375-385. [CrossRef]

3. Lindenmann, J.; Matzi, V.; Neuboeck, N.; Ratzenhofer-Komenda, B.; Maier, A.; Smolle-Juettner, F.-M. Severe hydrogen sulphide poisoning treated with 4-dimethylaminophenol and hyperbaric oxygen. Diving Hyperb. Med. 2010, 40, 213-217. [PubMed]

4. Beauchamp, R.O.; Bus, J.S.; Popp, J.A.; Boreiko, C.J.; Andjelkovich, D.A.; Leber, P. A critical review of the literature on hydrogen sulfide toxicity. Crit. Rev. Toxicol. 1984, 13, 25-97. [CrossRef]

5. OSHA Hydrogen Sulfide Hazards. Available online: https://www.osha.gov/SLTC/hydrogensulfide/hazards.html (accessed on 3 July 2020).

6. Powers, W. The Science of Smell Part 1: Odor Perception and Physiological Response; Iowa State University Extension: Ames, IA, USA, 2004.

7. Wang, R. Physiological implications of hydrogen sulfide: A whiff exploration that blossomed. Physiol. Rev. 2012, 92, 791-896. [CrossRef]

8. Montoya, L.A.; Shen, X.; McDermott, J.J.; Kevil, C.G.; Pluth, M.D. Mechanistic investigations reveal that dibromobimane extrudes sulfur from biological sulfhydryl sources other than hydrogen sulfide. Chem. Sci. 2015, 6, 294-300. [CrossRef] [PubMed]

9. Kimura, H.; Shibuya, N.; Kimura, Y. Hydrogen sulfide is a signaling molecule and a cytoprotectant. Antioxid. Redox Signal. 2012, 17, 45-57. [CrossRef]

10. Olson, K.R. A practical look at the chemistry and biology of hydrogen sulfide. Antioxid. Redox Signal. 2012, 17, 32-44. [CrossRef]

11. Khalid, T.Y.; Saad, S.; Greenman, J.; De Lacy Costello, B.; Probert, C.S.J.; Ratcliffe, N.M. Volatiles from oral anaerobes confounding breath biomarker discovery. J. Breath Res. 2013, 7. [CrossRef]

12. Jiménez, D.; Martínez-Máñez, R.; Sancenón, F.; Ros-Lis, J.V.; Benito, A.; Soto, J. A new chromo-chemodosimeter selective for sulfide anion. J. Am. Chem. Soc. 2003, 125, 9000-9001. [CrossRef] [PubMed]

13. Lei, W.; Dasgupta, P.K. Determination of sulfide and mercaptans in caustic scrubbing liquor. Anal. Chim. Acta 1989, 226, 165-170. [CrossRef]

14. Searcy, D.G.; Peterson, M.A. Hydrogen sulfide consumption measured at low steady state concentrations using a sulfidostat. Anal. Biochem. 2004, 324, 269-275. [CrossRef]

15. Lawrence, N.S.; Davis, J.; Jiang, L.; Jones, T.G.J.; Davies, S.N.; Compton, R.G. The electrochemical analog of the methylene blue reaction: A novel amperometric approach to the detection of hydrogen sulfide. Electroanalysis 2000, 12, 1453-1460. [CrossRef]

16. Radford-Knoery, J.; Cutter, G.A. Determination of Carbonyl Sulfide and Hydrogen Sulfide Species in Natural Waters Using Specialized Collection Procedures and Gas Chromatography with Flame Photometric Detection. Anal. Chem. 1993, 65, 976-982. [CrossRef]

17. Pandey, S.K.; Kim, K.-H.; Tang, K.-T. A review of sensor-based methods for monitoring hydrogen sulfide. TrAC Trends Anal. Chem. 2012, 32, 87-99. [CrossRef]

18. Wang, C.; $\mathrm{Chu}, \mathrm{X} . ; \mathrm{Wu}, \mathrm{M}$. Detection of $\mathrm{H} 2 \mathrm{~S}$ down to $\mathrm{ppb}$ levels at room temperature using sensors based on $\mathrm{ZnO}$ nanorods. Sens. Actuators B 2006, 113, 320-323. [CrossRef]

19. Advani, G.N.; Nanis, L. Effects of humidity on hydrogen sulfide detection by $\mathrm{SnO}_{2}$ solid state gas sensors. Sens. Actuators 1981, 2, 201-206. [CrossRef]

20. Liu, J.; Huang, X.; Ye, G.; Liu, W.; Jiao, Z.; Chao, W.; Zhou, Z.; Yu, Z. $\mathrm{H}_{2} \mathrm{~S}$ detection sensing characteristic of $\mathrm{CuO} / \mathrm{SnO} 2$ sensor. Sensors 2003, 3, 110. [CrossRef]

21. Sarfraz, J.; Ihalainen, P.; Määttänen, A.; Gulin, T.; Koskela, J.; Wilén, C.-E.; Kilpelä, A.; Peltonen, J. A printed $\mathrm{H}_{2} \mathrm{~S}$ sensor with electro-optical response. Sens. Actuators B 2014, 191, 821-827. [CrossRef]

22. Virji, S.; Kaner, R.B.; Weiller, B.H. Direct electrical measurement of the conversion of metal acetates to metal sulfides by hydrogen sulfide. Inorg. Chem. 2006, 45, 10467-10471. [CrossRef]

23. Rosolina, S.M.; Carpenter, T.S.; Xue, Z.-L. Bismuth-Based, Disposable Sensor for the Detection of Hydrogen Sulfide Gas. Anal. Chem. 2016, 88, 1553-1558. [CrossRef]

24. Sarfraz, J.; Tobjork, D.; Osterbacka, R.; Linden, M. Low-cost hydrogen sulfide gas sensor on paper substrates: Fabrication and demonstration. IEEE Sens. J. 2012, 12, 1973-1978. [CrossRef]

25. Fang, G.; Liu, Z.; Liu, C.; Yao, K.-L. Room temperature $\mathrm{H}_{2} \mathrm{~S}$ sensing properties and mechanism of $\mathrm{CeO}_{2}-\mathrm{SnO}_{2}$ sol-gel thin films. Sens. Actuators B 2000, 66, 46-48. [CrossRef]

26. Chowdhuri, A.; Gupta, V.; Sreenivas, K. Fast response H2S gas sensing characteristics with ultra-thin CuO islands on sputtered SnO2. Sens. Actuators B 2003, 93, 572-579. [CrossRef] 
27. Patil, L.A.; Patil, D.R. Heterocontact type $\mathrm{CuO}$-modified $\mathrm{SnO}_{2}$ sensor for the detection of a ppm level $\mathrm{H}_{2} \mathrm{~S}$ gas at room temperature. Sens. Actuators B 2006, 120, 316-323. [CrossRef]

28. Vaishampayan, M.V.; Deshmukh, R.G.; Walke, P.; Mulla, I.S. Fe-doped $\mathrm{SnO}_{2}$ nanomaterial: A low temperature hydrogen sulfide gas sensor. Mater. Chem. Phys. 2008, 109, 230-234. [CrossRef]

29. Gao, B.; Cui, L.; Pan, Y.; Xue, M.; Zhu, B.; Zhang, G.; Zhang, C.; Shuang, S.; Dong, C. A highly selective fluorescent probe based on Michael addition for fast detection of hydrogen sulfide. Spectrochim. Acta Part A Mol. Biomol. Spectrosc. 2017, 173, 457-461. [CrossRef]

30. Pla-Tolós, J.; Moliner-Martínez, Y.; Verdú-Andrés, J.; Casanova-Chafer, J.; Molins-Legua, C.; Campíns-Falcó, P. New optical paper sensor for in situ measurement of hydrogen sulphide in waters and atmospheres. Talanta 2016, 156-157, 79-86. [CrossRef]

31. Petruci, J.F.D.S.; Cardoso, A.A. Sensitive luminescent paper-based sensor for the determination of gaseous hydrogen sulfide. Anal. Methods 2015, 7, 2687-2692. [CrossRef]

32. Choi, M.M.F.; Hawkins, P. Development of an optical hydrogen sulphide sensor. Sens. Actuators B 2003, 90, 211-215. [CrossRef]

33. Toda, K.; Ohira, S.-I.; Tanaka, T.; Nishimura, T.; Dasgupta, P.K. Field Instrument for Simultaneous Large Dynamic Range Measurement of Atmospheric Hydrogen Sulfide, Methanethiol, and Sulfur Dioxide. Environ. Sci. Technol. 2004, 38, 1529-1536. [CrossRef] [PubMed]

34. Toda, K.; Dasgupta, P.K.; Li, J.; Tarver, G.A.; Zarus, G.M. Fluorometric field instrument for continuous measurement of atmospheric hydrogen sulfide. Anal. Chem. 2001, 73, 5716-5724. [CrossRef] [PubMed]

35. Petruci, J.F.D.S.; Cardoso, A.A. Portable and Disposable Paper-Based Fluorescent Sensor for in Situ Gaseous Hydrogen Sulfide Determination in Near Real-Time. Anal. Chem. 2016, 88, 11714-11719. [CrossRef]

36. Kubaáň, V.; Dasgupta, P.K.; Marx, J.N. Nitroprusside and Methylene Blue Methods for Silicone Membrane Differentiated Flow Injection Determination of Sulfide in Water and Wastewater. Anal. Chem. 1992, 64, 36-43. [CrossRef]

37. Fischer, E. Bildung von Methylenblau als Reaktion auf Schwefelwasserstoff. Berichte Dtsch. Chem. Gesellschaft 1883, 16, 2234-2236. [CrossRef]

38. Sen, A.; Albarella, J.D.; Carey, J.R.; Kim, P.; McNamara, W.B., III. Low-cost colorimetric sensor for the quantitative detection of gaseous hydrogen sulfide. Sens. Actuators B 2008, 134, 234-237. [CrossRef]

39. Wallace, K.J.; Cordero, S.R.; Tan, C.P.; Lynch, V.M.; Anslyn, E.V. A colorimetric response to hydrogen sulfide. Sens. Actuators B 2007, 120, 362-367. [CrossRef]

40. Tanaka, Y.; Nakamoto, T.; Moriizumi, T. Study of highly sensitive smell sensing system using gas detector tube combined with optical sensor. Sens. Actuators B 2006, 119, 84-88. [CrossRef]

41. Ninh, H.P.; Tanaka, Y.; Nakamoto, T.; Hamada, K. A bad-smell sensing network using gas detector tubes and mobile phone cameras. Sens. Actuators B 2007, 125, 138-143. [CrossRef]

42. Jarosz, A.P.; Yep, T.; Mutus, B. Microplate-based colorimetric detection of free hydrogen sulfide. Anal. Chem. 2013, 85, 3638-3643. [CrossRef] [PubMed]

43. Yuan, Z.; Lu, F.; Peng, M.; Wang, C.-W.; Tseng, Y.-T.; Du, Y.; Cai, N.; Lien, C.-W.; Chang, H.-T.; He, Y.; et al. Selective Colorimetric Detection of Hydrogen Sulfide Based on Primary Amine-Active Ester Cross-Linking of Gold Nanoparticles. Anal. Chem. 2015, 87, 7267-7273. [CrossRef]

44. Cha, J.-H.; Kim, D.-H.; Choi, S.-J.; Koo, W.-T.; Kim, I.-D. Sub-Parts-per-Million Hydrogen Sulfide Colorimetric Sensor: Lead Acetate Anchored Nanofibers toward Halitosis Diagnosis. Anal. Chem. 2018, 90, 8769-8775. [CrossRef]

45. Liu, Y.; Feng, G. A visible light excitable colorimetric and fluorescent ESIPT probe for rapid and selective detection of hydrogen sulfide. Org. Biomol. Chem. 2014, 12, 438-445. [CrossRef] [PubMed]

46. Zhang, D.; Jin, W. Highly selective and sensitive colorimetric probe for hydrogen sulfide by a copper (II) complex of azo-dye based on chemosensing ensemble approach. Spectrochim. Acta Part A Mol. Biomol. Spectrosc. 2012, 90, 35-39. [CrossRef] [PubMed]

47. Adarsh, N.; Krishnan, M.S.; Ramaiah, D. Sensitive naked eye detection of hydrogen sulfide and nitric oxide by aza-BODIPY dyes in aqueous medium. Anal. Chem. 2014, 86, 9335-9342. [CrossRef] [PubMed]

48. Engel, L.; Tarantik, K.R.; Pannek, C.; Wöllenstein, J. Colorimetric Detection of Hydrogen Sulfide in Ambient Air. Proceedings 2018, 2, 804. [CrossRef]

49. Fu, H.; Duan, X. Highly sensitive and colorimetric detection of hydrogen sulphide by in situ formation of Ag2S@Ag nanoparticles in polyelectrolyte multilayer film. RSC Adv. 2015, 5, 3508-3511. [CrossRef]

50. Zhang, Z.; Chen, Z.; Wang, S.; Qu, C.; Chen, L. On-site visual detection of hydrogen sulfide in air based on enhancing the stability of gold nanoparticles. ACS Appl. Mater. Interfaces 2014, 6, 6300-6307. [CrossRef]

51. Deng, H.-H.; Weng, S.-H.; Huang, S.-L.; Zhang, L.-N.; Liu, A.-L.; Lin, X.-H.; Chen, W. Colorimetric detection of sulfide based on target-induced shielding against the peroxidase-like activity of gold nanoparticles. Anal. Chim. Acta 2014, 852, $218-222$. [CrossRef]

52. El Sayed, S.; Milani, M.; Licchelli, M.; Martínez-Máñez, R.; Sancenón, F. Hexametaphosphate-capped silica mesoporous nanoparticles containing CuII complexes for the selective and sensitive optical detection of hydrogen sulfide in water. Chem. Eur. J. 2015, 21, 7002-7006. [CrossRef] [PubMed]

53. Tang, D.; Gao, Z.; Tang, D.; Niessner, R.; Knopp, D. Target-Induced Nanocatalyst Deactivation Facilitated by Core at Shell Nanostructures for Signal-Amplified Headspace-Colorimetric Assay of Dissolved Hydrogen Sulfide. Anal. Chem. 2015, 87, 10153-10160. [CrossRef] 
54. Puacz, W.; Szahun, W.; Linke, K. Catalytic determination of sulfide in blood. Analyst 1995, 120, 939-941. [CrossRef]

55. Xu, H.; Wu, J.; Chen, C.-H.; Zhang, L.; Yang, K.-L. Detecting hydrogen sulfide by using transparent polymer with embedded CdSe/CdS quantum dots. Sens. Actuators B 2010, 143, 535-538. [CrossRef]

56. Bhadra, N.; Hussain, S.; Das, S.; Bhunia, R.; Bhar, R.; Pal, A.K. $\mathrm{H}_{2} \mathrm{~S}$ Gas Sensor Based on Nanocrystalline Copper/DLC Composite Films. Plasmonics 2015, 10, 503-509. [CrossRef]

57. Ravi, P.V.; Thangadurai, D.T.; Nataraj, D.; Senthilkumar, K.; Manonmani, G.; Kalarikkal, N.; Thomas, S.; Govindh, P. Graphene Nanobuds: A New Second-Generation Phosgene Sensor with Ultralow Detection Limit in Aqueous Solution. ACS Appl. Mater. Interfaces 2019, 11, 19339-19349. [CrossRef]

58. Yu, F.; Li, P.; Song, P.; Wang, B.; Zhao, J.; Han, K. An ICT-based strategy to a colorimetric and ratiometric fluorescence probe for hydrogen sulfide in living cells. Chem. Commun. 2012, 48, 2852-2854. [CrossRef]

59. Zhao, Y.; Zhu, X.; Kan, H.; Wang, W.; Zhu, B.; Du, B.; Zhang, X. A highly selective colorimetric chemodosimeter for fast and quantitative detection of hydrogen sulfide. Analyst 2012, 137, 5576-5580. [CrossRef]

60. Wu, M.-Y.; Li, K.; Hou, J.-T.; Huang, Z.; Yu, X.-Q. A selective colorimetric and ratiometric fluorescent probe for hydrogen sulfide. Org. Biomol. Chem. 2012, 10, 8342-8347. [CrossRef] [PubMed]

61. Gu, X.; Liu, C.; Zhu, Y.-C.; Zhu, Y.-Z. Development of a boron-dipyrromethene-Cu ${ }^{2+}$ ensemble based colorimetric probe toward hydrogen sulfide in aqueous media. Tetrahedron Lett. 2011, 52, 5000-5003. [CrossRef]

62. Liu, J.; Sun, Y.-Q.; Zhang, J.; Yang, T.; Cao, J.; Zhang, L.; Guo, W. A ratiometric fluorescent probe for biological signaling molecule H 2S: Fast response and high selectivity. Chem. Eur. J. 2013, 19, 4717-4722. [CrossRef] [PubMed]

63. Narayanaswamy, R.; Sevilla, F., III. Umist Flow cell studies with immobilised reagents for the development of an optical fibre sulphide sensor. Analyst 1986, 3, 1085-1088. [CrossRef]

64. Maiti, S.; Mandal, B.; Sharma, M.; Mukherjee, S.; Das, A.K. A covalent organic polymer as an efficient chemosensor for highly selective H2S detection through proton conduction. Chem. Commun. 2020. [CrossRef]

65. Sensidyne Hydrogen Sulphide 1-60 ppm Gas Detector Tube. Available online: https:/ / www.sensidyne.com/colorimetric-gasdetector-tubes/detector-tubes/120sd-hydrogen-sulphide.php (accessed on 3 July 2020).

66. Gastec Corporation Hydrogen Sulphide Detector Tube 4HT. Available online: https://www.gastec.co.jp/en/product/detail/id= 1799 (accessed on 3 July 2020).

67. Huang, L.; Jiang, P.; Wang, D.; Luo, Y.; Li, M.; Lee, H.; Gerhardt, R.A. A novel paper-based flexible ammonia gas sensor via silver and SWNT-PABS inkjet printing. Sens. Actuators B 2014, 197, 308-313. [CrossRef]

68. Cuartero, M.; Crespo, G.A.; Bakker, E. Paper-based thin-layer coulometric sensor for halide determination. Anal. Chem. 2015, 87, 1981-1990. [CrossRef]

69. Chaiyo, S.; Siangproh, W.; Apilux, A.; Chailapakul, O. Highly selective and sensitive paper-based colorimetric sensor using thiosulfate catalytic etching of silver nanoplates for trace determination of copper ions. Anal. Chim. Acta 2015, 866, 75-83. [CrossRef]

70. Su, Y.; Ma, S.; Jiang, K.; Han, X. CdTe-paper-based visual sensor for detecting methyl viologen. Chin. J. Chem. 2015, 33, 446-450. [CrossRef]

71. Ferreira, D.C.M.; Giordano, G.F.; Soares, C.C.D.S.P.; De Oliveira, J.F.A.; Mendes, R.K.; Piazzetta, M.H.; Gobbi, A.L.; Cardoso, M.B. Optical paper-based sensor for ascorbic acid quantification using silver nanoparticles. Talanta 2015, 141, 188-194. [CrossRef]

72. Firdaus, M.L.; Alwi, W.; Trinoveldi, F.; Rahayu, I.; Rahmidar, L.; Warsito, K. Determination of Chromium and Iron Using Digital Image-based Colorimetry. Procedia Environ. Sci. 2014, 20, 298-304. [CrossRef]

73. Masawat, P.; Harfield, A.; Srihirun, N.; Namwong, A. Green Determination of Total Iron in Water by Digital Image Colorimetry. Anal. Lett. 2017, 50, 173-185. [CrossRef]

74. Puchum, S.; Meelapsom, R.; Muniandy, S.S.; Lee, H.L.; Pencharee, S.; Amatatongchai, M.; Suttisintong, K.; Jarujamrus, P. Use of unmodified silver nanoparticles (AgNPs) as colorimetric $\mathrm{Hg}(\mathrm{II})$ sensor: A new approach to sensitive and high sample throughput determination of $\mathrm{Hg}$ (II) under high influence of ionic suppression. Int. J. Environ. Anal. Chem. 2019, 99, 139-156. [CrossRef]

75. Salcedo, A.R.M.; Sevilla, F.B. Colorimetric determination of mercury vapor using smartphone camera-based imaging. Instrum. Sci. Technol. 2018, 46, 450-462. [CrossRef]

76. Choodum, A.; Boonsamran, P.; NicDaeid, N.; Wongniramaikul, W. On-site semi-quantitative analysis for ammonium nitrate detection using digital image colourimetry. Sci. Justice 2015, 55, 437-445. [CrossRef]

77. David, T.; Grandivoriana, N.A.; Fidelis, N. Digital-based image detection system in simple silver nanoparticles-based cyanide assays. Res. J. Chem. Environ. 2018, 22, 10-14.

78. Choodum, A.; Parabun, K.; Klawach, N.; Daeid, N.N.; Kanatharana, P.; Wongniramaikul, W. Real time quantitative colourimetric test for methamphetamine detection using digital and mobile phone technology. Forensic Sci. Int. 2014, 235, 8-13. [CrossRef]

79. Wongniramaikul, W.; Limsakul, W.; Choodum, A. A biodegradable colorimetric film for rapid low-cost field determination of formaldehyde contamination by digital image colorimetry. Food Chem. 2018, 249, 154-161. [CrossRef]

80. Tambaru, D.; Rupilu, R.H.; Nitti, F.; Gauru, I. Suwari Development of paper-based sensor coupled with smartphone detector for simple creatinine determination. In Proceedings of the AIP Conference Proceedings, Bikaner, India, 24-25 November 2017; American Institute of Physics Inc.: Kupang, Indonesia, 2017; Volume 1823.

81. Priye, A.; Ball, C.S.; Meagher, R.J. Colorimetric-Luminance Readout for Quantitative Analysis of Fluorescence Signals with a Smartphone CMOS Sensor. Anal. Chem. 2018, 90, 12385-12389. [CrossRef] [PubMed] 
82. Fatoni, A.; Numnuam, A.; Kanatharana, P.; Limbut, W.; Thammakhet, C.; Thavarungkul, P. A highly stable oxygen-independent glucose biosensor based on a chitosan-albumin cryogel incorporated with carbon nanotubes and ferrocene. Sens. Actuators $B$ 2013, 185, 725-734. [CrossRef]

83. Shen, L.; Hagen, J.A.; Papautsky, I. Point-of-care colorimetric detection with a smartphone. Lab Chip 2012, 12, 4240-4243. [CrossRef] [PubMed]

84. Hong, J.I.; Chang, B.-Y. Development of the smartphone-based colorimetry for multi-analyte sensing arrays. Lab Chip 2014, 14, 1725-1732. [CrossRef]

85. Montoya, L.A.; Pearce, T.F.; Hansen, R.J.; Zakharov, L.N.; Pluth, M.D. Development of selective colorimetric probes for hydrogen sulfide based on nucleophilic aromatic substitution. J. Org. Chem. 2013, 78, 6550-6557. [CrossRef] [PubMed]

86. Montoya, L.A.; Pluth, M.D. Hydrogen sulfide deactivates common nitrobenzofurazan-based fluorescent thiol labeling reagents. Anal. Chem. 2014, 86, 6032-6039. [CrossRef] [PubMed]

87. Ismail, I.; Chen, Z.; Sun, L.; Ji, X.; Ye, H.; Kang, X.; Huang, H.; Song, H.; Bolton, S.G.; Xi, Z.; et al. Highly efficient $\mathrm{H}_{2} \mathrm{~S}$ scavengers: Via thiolysis of positively-charged NBD amines. Chem. Sci. 2020, 11, 7823-7828. [CrossRef]

88. Quddious, A.; Yang, S.; Khan, M.M.; Tahir, F.A.; Shamim, A.; Salama, K.N.; Cheema, H.M. Disposable, paper-based, inkjet-printed humidity and H2S gas sensor for passive sensing applications. Sensors 2016, 16, 2073. [CrossRef] [PubMed]

89. Rae Systems Colorimetric Gas Detection Tubes. Available online: https://www.raesystems.com/products/colorimetric-gasdetection-tubes-and-pump (accessed on 3 July 2020).

90. Sanderson, H.P.; Thomas, R.; Katz, M. Limitations of the lead acetate impregnated paper tape method for hydrogen sulfide. J. Air Pollut. Control Assoc. 1966, 16, 328-330. [CrossRef] [PubMed]

91. Innov Analysis Systems Hydrogen Sulphide Gas Analyser Novasulf Hg 300 Series. Available online: https://www.innovanalysis.com/images/pdf/notice_novasulfhg_en_300_rev0.pdf (accessed on 2 October 2020).

92. Nasr-El-Din, H.A.; Al-Humaidan, A.Y. Iron Sulfide Scale: Formation, Removal and Prevention; International Symposium on Oilfield Scale; Society of Petroleum Engineers: Aberdeen, UK, 2001. [CrossRef]

93. Bro, R.; Rinnan, Å.; Faber, N.M. Standard error of prediction for multilinear PLS 2. Practical implementation in fluorescence spectroscopy. Chemom. Intell. Lab. Syst. 2005, 75, 69-76. [CrossRef] 